\title{
A publicidade nos livros didáticos do Ensino Médio
}

\begin{abstract}
Maria Aparecida Baccega
Professora do mestrado da ESPM. Coordenadora adjunta do Programa de Mestrado em Comunicação e Práticas de Consumo (ESPM).

Professora associada aposentada da ECA-USP. Editora da revista Comunicação \& Educação, USP/Paulinas, de 1994 a 2005. Autora de artigos e livros, entre os quais: Comunicação $e$ linguagem: discursos e ciência (Moderna) e Televisão e escola: uma mediação possível? (Senac). E-mail: mabga@usp.br
\end{abstract}

Denise de Oliveira Freire

Jornalista especialista em Jornalismo Cultural pela PUC-SP e assistente de pesquisas acadêmicas no Programa de Mestrado em Comunicação e Práticas de Consumo da ESPM.

E-mail: denise-freire@hotmail.com

A importância da publicidade na formação do imaginário e na práxis cotidiana é constatável. Em função disso, este artigo procura verificar como ela tem estado presente no campo da Comunicação/Educação, especificamente do ponto de vista de sua inserção na educação formal. Para tanto, tomamos os anúncios publicitários inseridos nos livros didáticos de Português do Ensino Médio e procuramos saber como eles sugerem sua utilização no ensino em sala de aula.

\section{ANÁLISE DAS PUBLICIDADES PRESENTES NOS LIVROS DIDÁTICOS}

Consultamos, primeiramente, as editoras de São Paulo para saber quais os livros mais procurados pelas escolas. Segundo elas, os livros didáticos de Português mais utilizados nas escolas de Ensino Médio do Estado de São Paulo são dois, de formatos diferentes entre si: um, intitulado Português - da série Novo Ensino Médio, da Editora Ática -, apresenta-se em um volume único e é válido para as três séries; seu autor é João Domingues Maia, doutor e mestre em Letras pela PUC-RJ e especialista em Lingüística e em Teoria da Literatura, ambas pela UFRJ. O outro livro, Português: Linguagens, de autoria de William Roberto Cereja e Thereza Cochar Magalhães, compõe-se de três volumes e é publicado pela Atual Editora. Cereja é graduado em Português e Lingüística e licenciado em Português pela Universidade de São Paulo; mestre em Teoria 
1. Sobre o tema, veja: $O$ impacto da publicidade/ propaganda no campo da Comunicação/Educação. Cadernos de Pesquisa, São Paulo: ESPM, ano l, n. 3, set./out. 2005. A coleta de dados, financiada pela ESPM-SP, foi realizada entre 2004 e 2006, por uma equipe coordenada por Maria Aparecida Baccega e formada por dra. Maria Ignês Carlos Magno, Sílvia Alencar e Juscilene Alves de Oliveira (IC), e Gildo Macedo dos Santos (técnico), na 1a fase (coleta de dados); dr. Vander Casaqui, Cláudia Bredarioli e Denise Freire (especialistas), e Juscilene Alves de Oliveira (IC), na 2a fase (análise de parte dos dados); e dra. Yara Castro (estatística).
Literária, também pela USP; doutor em Lingüística Aplicada e Análise do Discurso pela PUC-SP; e professor da rede particular de ensino em São Paulo. Magalhães é professora graduada em Português e Francês e licenciada pela FFCL de Araraquara (SP); mestra em Estudos Literários pela Unesp de Araraquara; e professora da rede pública de ensino na mesma cidade.

Somente no final de 2006 tivemos a oportunidade de refletir sobre os dados levantados e redigir este texto, embora os dados se refiram aos livros que estavam em circulação em 2004, ano em que foram realizados outros levantamentos sobre publicidade e Ensino Médio, colhidos em escolas da rede ${ }^{1}$.

No decorrer da observação das formas de utilização da publicidade pelos livros didáticos analisados, encontramos as ocorrências apontadas na tabela abaixo:

\begin{tabular}{|c|c|c|}
\hline \multicolumn{1}{|c|}{ LIVROS } & OCORRÊNCIAS & $\begin{array}{c}\text { PUBLICIDADES } \\
\text { ENCONTRADAS }\end{array}$ \\
\hline Volume único & 13 & $17 \%$ \\
\hline Volume 1 & 19 & $25 \%$ \\
\hline Volume 2 & 26 & $34 \%$ \\
\hline Volume 3 & 18 & $24 \%$ \\
\hline TOTAL & 76 & $100 \%$ \\
\hline
\end{tabular}

Com base nas publicidades colhidas nesses livros, através de uma análise primeiramente quantitativa e, após, qualitativa, procuramos mostrar os modos recorrentes de exploração dos anúncios publicitários no processo ensino/aprendizagem, a fim de verificar seu modo de utilização em sala de aula. Para tanto, foram retirados trechos dos livros utilizados.

Além dessa avaliação do conteúdo programático nos livros didáticos, verificamos também os veículos de mídia dos quais as mensagens publicitárias foram retiradas e quais os produtos anunciados.

\section{COMO FOI CONSTITUÍDO O PERCURSO}

Através de uma análise, primeiramente quantitativa e, depois, qualitativa, dividimos os modos de utilização das publicidades apresentadas nos livros didáticos de Português em nove categorias, apontando a ordem de freqüência de aparição de tais publicidades.

\section{Divisão das publicidades em categorias}

1. Gramática e figuras de linguagem: estão classificadas nesta categoria as publicidades que se destinaram tão-somente ao ensino da gramática, como exemplos da correta utilização do idioma, além das apropriações de figuras de linguagem, como, por exemplo, ambigüidade, feitas pela publicidade na tentativa de ressaltar sua mensagem. 
2. Atividades: engloba todos os anúncios utilizados como atividades de aprendizagem, a serem realizadas pelos alunos, do conteúdo apresentado no capítulo em que eles se encontram. Esta categoria está dividida em quatro subcategorias relacionadas ao uso dos anúncios nas atividades didáticas: questão de vestibular, produção de texto, opinião pessoal e estrutura narrativa.

3. Linguagem verbal: esta categoria trata da utilização da confluência da linguagem verbal com as linguagens não-verbais, como cores utilizadas, modo de disposição das figuras, traços etc., e suas relações com a palavra.

4. Exemplificação: esta categoria enfoca a publicidade apenas como forma de exemplificar o conteúdo didático apresentado no respectivo capítulo.

5. Público-alvo: esta categoria leva o aluno, através de questionário, a buscar a identificação do público-alvo da publicidade apresentada.

6. Persuasão e objetivo da peça: aborda os mecanismos de persuasão da publicidade relacionados ao objetivo daquela peça publicitária.

7. Sugestão ao professor: agrupa as sugestões dadas pelo livro didático ao professor, como modos de abordagens da publicidade em sala de aula, possíveis referências para apresentar aos alunos, entre outras sugestões.

8. Outros: esta categoria engloba alguns assuntos minoritariamente abordados, relacionados às publicidades apresentadas, tais como formas de atuação da publicidade, a que se refere a promoção do anúncio (bem material ou simbólico, como campanha de saúde), entre outras.

\begin{tabular}{|c|c|c|c|c|c|c|}
\hline \multicolumn{7}{|c|}{ FORMAS DE UTILIZAÇÃO DA PUBLICIDADE } \\
\hline & CATEGORIAS & TOTAL & $\begin{array}{l}\text { VOLUME } \\
\text { ÚNICO }\end{array}$ & $\begin{array}{c}\text { VolUME } \\
1\end{array}$ & $\begin{array}{l}\text { VOLUME } \\
2\end{array}$ & $\begin{array}{l}\text { VOLUME } \\
3\end{array}$ \\
\hline 1 & $\begin{array}{l}\text { Gramática e figuras de } \\
\text { linguagem }\end{array}$ & 65 & 12 & 14 & 23 & 16 \\
\hline \multirow[t]{5}{*}{2} & Atividades & 52 & 10 & 16 & 17 & 9 \\
\hline & Questão de vestibular & 6 & 5 & - & 1 & - \\
\hline & Produção de texto & 4 & - & 1 & 2 & 1 \\
\hline & Opinião pessoal & 12 & - & 6 & 4 & 2 \\
\hline & Estrutura narrativa & 5 & 4 & 1 & - & - \\
\hline \multirow[t]{2}{*}{3} & Linguagem verbal & 24 & 5 & 15 & 3 & 1 \\
\hline & Linguagens não-verbais & 24 & 5 & 15 & 3 & 1 \\
\hline 4 & Exemplificação & 25 & 5 & 2 & 9 & 9 \\
\hline 5 & Público-alvo & 11 & 1 & 7 & 2 & 1 \\
\hline \multirow[t]{2}{*}{6} & Persuasão & 9 & 3 & 5 & 1 & - \\
\hline & Objetivo da peça & 4 & - & 3 & - & 1 \\
\hline 7 & Sugestão ao professor & 8 & - & 8 & - & - \\
\hline 8 & Outros & 9 & 4 & 3 & - & 2 \\
\hline
\end{tabular}


comunicação \& educação • Ano XII • Número 2 • maio/ago 2007

É importante ressaltar que as publicidades apresentadas nos livros didáticos apresentam várias dessas categorias ao mesmo tempo, ou seja, uma mesma publicidade pode reunir as categorias atividades, opinião pessoal, linguagens verbal e não-verbal, e assim por diante.

\section{Veículos onde as publicidades foram originalmente transmitidas}

As publicações em que as publicidades presentes nos livros didáticos foram originalmente veiculadas totalizam 29, entre jornais e revistas.

Uma diferença a ser ressaltada entre os dois livros didáticos é que, enquanto o seriado informa onde as publicidades foram divulgadas originalmente, o de volume único só o faz em uma ocasião. Sendo assim, entre as publicidades enquadradas na categoria sem especificação encontram-se, além das presentes no volume único, campanhas de utilização pública (enfoque social).

Dentre os 29 veículos citados, podemos verificar que predominam as revistas impressas, voltadas majoritariamente para os públicos A e B, com idade superior a 20 anos. Em algumas publicações, como as revistas Carta Capital, Próxima Viagem, Superinteressante e Arquitetura e Construção, os leitores das classes A e B ultrapassam os $80 \%$.

Entre as publicações destinadas especificamente ao público teen estão: Mundo Estranho, Capricho, Atrevida e a já extinta Antenada.

Com quase 80 mil exemplares, Mundo Estranho tem $75 \%$ dos seus leitores situados nas classes A e B. Já as revistas Capricho (103.834 exemplares) e Atrevi$d a$ (101.517 exemplares) apresentam uma porcentagem mais equilibrada entre leitores das classes $\mathrm{AB}$ e $\mathrm{CD}$, girando em torno de $50 \%$ cada.

$\mathrm{O}$ veículo que aparece com maior freqüência nos anúncios selecionados pelos livros didáticos é a revista semanal Veja, com 17 referências, sendo que seus dois suplementos também foram utilizados: Veja São Paulo e Veja Kids+.

Em relação à revista Veja, sua tiragem semanal ultrapassa 1 milhão de exemplares, distribuídos nacionalmente, $70 \%$ de seus leitores pertencem às classes $\mathrm{AB}$ e apenas $21 \%$ têm entre 10 e 19 anos. Já a Veja São Paulo, com tiragem de 350 mil exemplares, tem distribuição regional, $80 \%$ dos seus leitores situam-se nas classes A e B e somente $15 \%$ tem idade entre 10 e 19 anos $^{2}$. Percebemos que a origem editorial dos anúncios escolhidos está bastante distante da realidade dos alunos a quem se dirigem tais livros didáticos.

2. Dados fornecidos pelas agências de publicidade da cidade de São Paulo-SP. 
A publicidade nos livros didáticos - Maria A. Baccega e Denise de Oliveira Freire

\begin{tabular}{|c|c|c|c|c|c|}
\hline \multicolumn{6}{|c|}{ VEÍCULOS DOS QUAIS AS PUBLICIDADES FORAM RETIRADAS } \\
\hline Veículos & TOTAL & $\begin{array}{l}\text { VOLUME } \\
\text { ÚNICO* }\end{array}$ & VOLUME 1 & Volume 2 & VOLUME 3 \\
\hline Veja & 17 & - & 6 & 9 & 2 \\
\hline Claudia & 5 & - & 4 & 1 & - \\
\hline Época & 3 & - & 1 & 1 & 1 \\
\hline Mundo Estranho & 3 & - & 1 & 1 & 1 \\
\hline Carta Capital & 3 & - & - & 2 & 1 \\
\hline Ícaro Brasil & 3 & - & - & 1 & 2 \\
\hline Veja São Paulo & 2 & - & 1 & - & 1 \\
\hline Espaço D' & 2 & - & - & 1 & 1 \\
\hline Capricho & 2 & - & - & 1 & 1 \\
\hline Marie Claire & 2 & - & - & 1 & 1 \\
\hline Arquitetura e Construção & 2 & - & - & 2 & - \\
\hline Terra da Gente & 2 & - & - & - & 2 \\
\hline Caras & 1 & 1 & - & - & - \\
\hline Antenada & 1 & - & 1 & - & - \\
\hline Náutica & 1 & - & 1 & - & - \\
\hline Próxima Viagem & 1 & - & 1 & - & - \\
\hline Veja Kids+ & 1 & - & 1 & - & - \\
\hline Atrevida & 1 & - & - & 1 & - \\
\hline Superinteressante & 1 & - & - & 1 & - \\
\hline Próxima Viagem & 1 & - & - & 1 & - \\
\hline Contigo & 1 & - & - & 1 & - \\
\hline Construir & 1 & - & - & 1 & - \\
\hline Isto É - São Paulo & 1 & - & - & - & 1 \\
\hline Nova & 1 & - & - & - & 1 \\
\hline Viver Bem & 1 & - & - & - & 1 \\
\hline Casa Claudia & 1 & - & - & - & 1 \\
\hline Folha de S. Paulo & 1 & - & 1 & - & - \\
\hline Diário Popular & 1 & - & - & 1 & - \\
\hline Globo & 1 & - & - & 1 & - \\
\hline Sem especificação & 15 & - & $2^{3}$ & - & $1^{4}$ \\
\hline
\end{tabular}

* Única referência de veículo encontrada no livro didático.

3. 1) Campanha comunitária sobre utilização correta de receitas médicas. Apoio: Schering-Plough 2) Campanha comunitária sobre combate à dengue promovida pelo Ministério da Saúde.

4. Campanha incentivando o uso da camisinha durante o Carnaval, promovida pelo Ministério da Saúde. 
comunicação \& educação • Ano XII • Número 2 • maio/ago 2007

\section{Produtos anunciados}

\begin{tabular}{|c|c|c|c|c|c|}
\hline \multicolumn{6}{|c|}{ PRODUTOS ANUNCIADOS NAS PUBLICIDADES ${ }^{5}$} \\
\hline PRODUTOS & TOTAL & $\begin{array}{l}\text { VOLUME } \\
\text { ÚNICO }\end{array}$ & $\begin{array}{c}\text { VOLUME } \\
1\end{array}$ & $\begin{array}{l}\text { VOLUME } \\
2\end{array}$ & $\begin{array}{l}\text { VOLUME } \\
3\end{array}$ \\
\hline Alimentos & 17 & 11 & - & 6 & - \\
\hline Automóveis e acessórios & 12 & 9 & 2 & 1 & - \\
\hline Casa/Decoração/Construção & 10 & 1 & - & 3 & 6 \\
\hline Utilidades domésticas & 9 & 6 & 2 & 1 & - \\
\hline $\begin{array}{l}\text { Viagens - companhia de } \\
\text { aviação e agências de turismo }\end{array}$ & 7 & 1 & 1 & 3 & 2 \\
\hline Higiene pessoal & 6 & 5 & - & - & 1 \\
\hline Calçados & 5 & 2 & 2 & - & 1 \\
\hline Campanhas & 5 & - & 3 & - & 2 \\
\hline Imprensa & 5 & - & 3 & 1 & 1 \\
\hline Banco & 5 & 2 & - & 2 & 1 \\
\hline Produtos escolares & 3 & 1 & 1 & 1 & - \\
\hline Empresas & 3 & 1 & 1 & 1 & - \\
\hline Roupas & 2 & 1 & 1 & - & - \\
\hline Eletrodomésticos & 2 & 1 & - & - & 1 \\
\hline Remédio & 2 & 2 & - & - & - \\
\hline Seguro & 2 & 2 & - & - & - \\
\hline Outros & 19 & 3 & 4 & 9 & 3 \\
\hline
\end{tabular}

Em relação aos produtos presentes nos anúncios publicitários inseridos nos livros didáticos, optamos por dividi-los em 17 tipos, arrolados por ordem de freqüência de aparição - Alimentos (17 referências): de bebidas, como sucos e refrigerantes, chocolate e iogurte, até cereal matinal e biscoitos; Automóveis e Acessórios (12): de carros e motos, aos acessórios em geral, que vão de pneus até lubrificantes; Casa/Decoração/Construção (10): de duchas, móveis, tintas, loja

5. A especificação dos produtos pode ser conhecida solicitando-se os dados para a equipe, coordenada por Maria Aparecida Baccega, do Programa de Mestrado em Comunicação e Práticas de Consumo da Escola Superior de Propaganda e Marketing - ESPM. de material de construção e roupa de cama, mesa e banho; Utilidades domésticas (9): de produtos destinados à limpeza doméstica, como sabão em pó e papel higiênico, a utensílios para a organização do lar, como recipientes plásticos; Viagens (7): companhias de aviação e agências de turismo, assim como pacotes de viagens e destinos; Higiene pessoal (6): sabonete, desodorante, perfume, bronzeador e pasta de dente; Calçados (5): sandálias e sapatos; Campanhas (5): de enfoque social, como Ação Criança, Dengue e Prevenção da Aids; Imprensa (5): Guia Quatro Rodas e revista Superinteressante; Banco (5): cartão de crédito, 
bem como institucionais das agências; Produtos Escolares (3): canetas e corretivos; Empresas (3): institucionais de empresas, como Compaq e Cemig; Roupas (2): marca de roupas, desde as destinadas ao público adulto até o infantil, sem referências a marcas que foquem o público adolescente; Eletrodomésticos (2): propagandas que normalmente não estão ao alcance da maioria dos jovens do Ensino Médio; Remédio (2): pomada e um laboratório farmacêutico; Seguro (2): seguros de saúde; Outros (19): dizem respeito a produtos que só apareceram uma vez, como escola particular, hotel, lançamento imobiliário e internet, além dos que se referem a concursos culturais, festival, aniversário do Rio de Janeiro, Doutores da Alegria e assim por diante.

\section{Presença da publicidade no livro didático}

A justificativa dada por autores e editoras para a utilização dos anúncios publicitários nos livros didáticos é a de aproximar a educação formal do cotidiano dos adolescentes, porém as peças presentes nos livros analisados nem sempre se revelam adequadas para a faixa etária dos alunos.

Vejamos o caso do anúncio da companhia de aviação South African Airlines $^{6}$, veiculado originalmente na revista Espaço $D$ ', que se autodefine como sendo de arquitetura, decoração e modo de vida. A viagem sugerida era para a África do Sul, cidade do Cabo, como podemos notar através do enunciado reproduzido pelo Volume 2 de Português: Linguagens: "Se você quer conhecer bem a África do Sul, é melhor começar pelo Cabo". A imagem que acompanha

\section{SE VOCÊ QUER CONHECER BEM} A ÁFrICA DO SUL

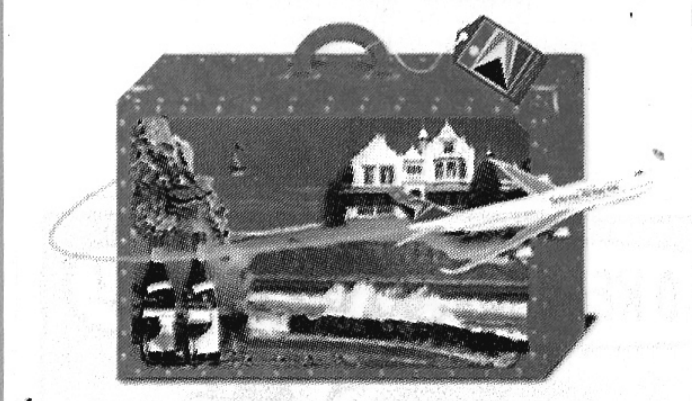

É MELHOR COMEÇAR PELO CABO.

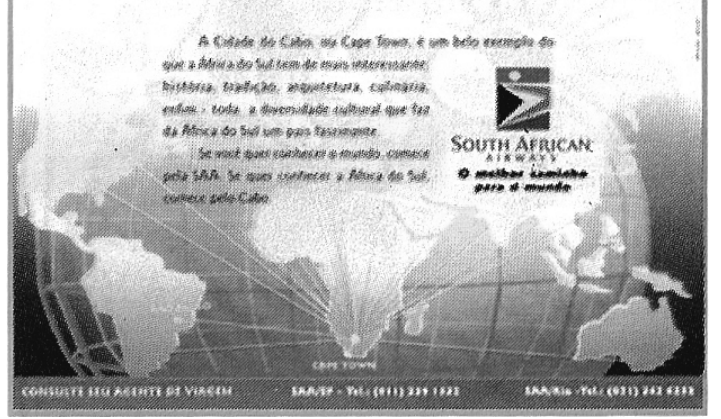

o enunciado traz uma mala, um avião e um globo terrestre com conexões para o mundo todo saindo da África do Sul. Certamente esta viagem não se configura um destino prioritário na vida da maioria dos adolescentes.

Já o Volume 3 do livro didático Português: Linguagens apresenta uma publicidade da loja de móveis e decoração Tok \& Stok ${ }^{7}$, publicada na revista Veja São Paulo. Inserido no capítulo 35 - Lingua: uso e reflexão - Regência verbal e nominal -, o enunciado da publicidade serve de base para um exercício sobre a correta utilização da crase. Tanto a loja quanto a revista não podem ser consideradas populares: a primeira,
6. CEREJA, William Roberto; MAGALHÃES, Thereza Cochar. Português: Linguagens. 4. ed. rev. e ampl. São Paulo: Atual, 2004. v. 2, p. 204.

7. Id. Português: Linguagens. 4. ed. rev. e ampl. São Paulo: Atual, 2004. v. 3 , p. 84 . 
por causa do preço e do design sofisticado; e a segunda, pelo alcance restrito, já que circula apenas na Grande São Paulo, como encarte da revista Veja, sendo que $80 \%$ de seus leitores pertencem às classes $\mathrm{A}$ e $\mathrm{B}$.

$\mathrm{O}$ anúncio publicado no livro didático é referente aos guarda-sóis no valor de $\mathrm{R} \$ 58,00$ a unidade. Da linha Garden Tok \& Stok, é destinado a um consumidor que possua um espaço ao ar livre em sua casa ou ainda desfrute de férias na praia.

Embora o público infantojuvenil esteja gradativamente participando com maior poder de decisão, devido a sua influência nas compras familiares, e o universo de consumo esteja mais ligado à classe social do que à idade biológica propriamente dita, os produtos apresentados nos anúncios publicitários presentes nos livros didáticos analisados parecem estar fora do universo da maioria dos adolescentes; é o caso de companhias de aviação e viagens, lançamento imobiliário, móveis de alto padrão, artigos de decoração, automóveis de luxo,

DÊ PARA SUA MÃE UM PRESENTE QUE DURA MAIS QUE UMA SEMANA. laboratórios farmacêuticos, car-
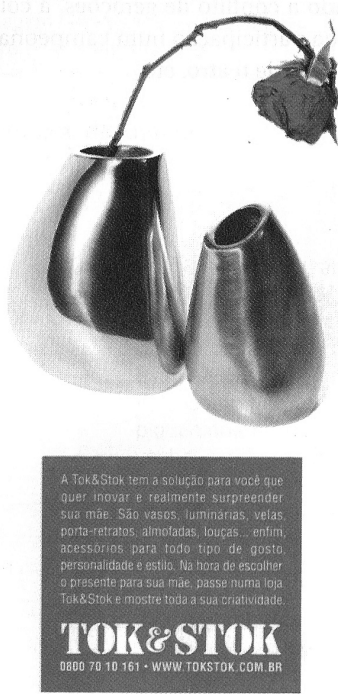
tão de crédito, tinta de parede, azeite de oliva, sabão em pó, tapetes e carpetes, toalhas de banho, motocicleta e eletrodomésticos. Ou seja, a maioria dos produtos não faz parte do imaginário dos adolescentes e, dessa forma, não constituem prioridade de consumo do jovem estudante, com algumas exceções. Sendo assim, não representam a desejada aproximação da escola ao cotidiano dos jovens estudantes.

Da mesma forma, os veículos de comunicação em que os anúncios publicitários foram originalmente difundidos estão tão distantes do imaginário cultural da maioria dos adolescentes do Ensino Médio, quanto os produtos por eles anunciados. Revistas como Casa Claudia, Náutica, Claudia, Nova, Ícaro, Próxima Viagem, Espaço D', Arquitetura e Construção, Marie Claire, Carta Capital, Construir, Terra da Gente e Viver Bem não têm como público-alvo os adolescentes, conforme dados obtidos das agências de publicidade sobre os veículos pesquisados. Serão os anúncios escolhidos para agradar aos pais?

Se as publicidades inseridas nos livros didáticos procurassem se aproximar mais do universo cultural dos estudantes, isso poderia possibilitar aos autores a elaboração de uma melhor análise crítica do conteúdo apresentado. 


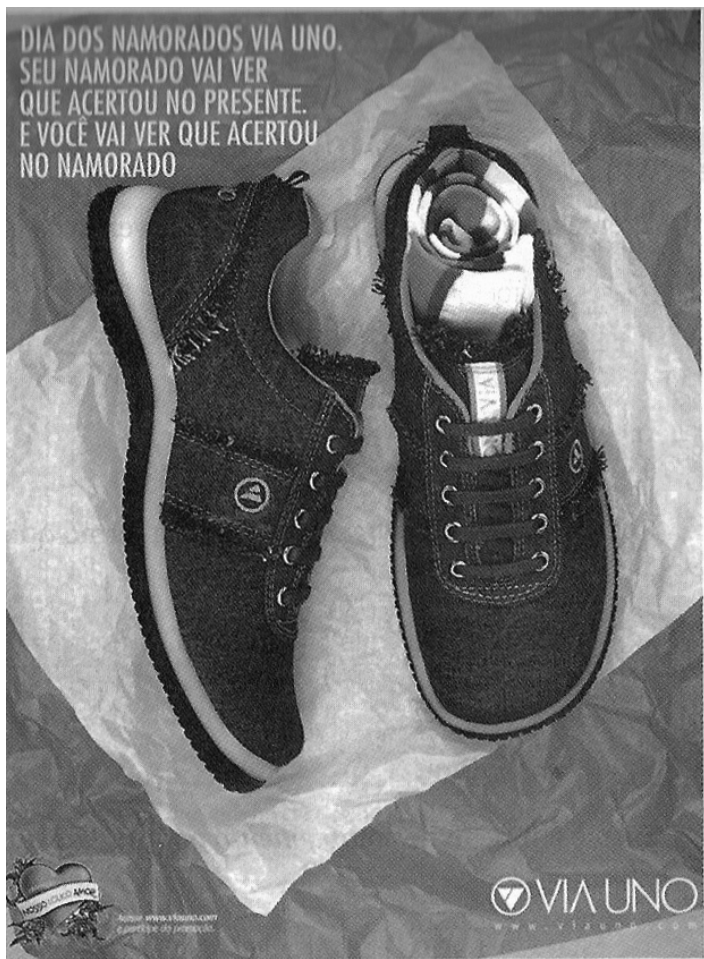

\section{Adequação}

Um dos poucos exemplos de adequação ao imaginário teen é o anúncio da Via Uno, publicado na revista Capricho $(2002)^{8}$ e presente no Volume 3 do livro Português: Linguagens. Tendo como públicoalvo adolescentes do sexo feminino, a revista veiculou o anúncio de calçados na época do Dia dos Namorados. Este foi apropriado pelo livro didático para exemplificar o emprego da conjunção integrante que. Exibindo a foto de um par de calçados, apresenta a seguinte frase: "Dia dos Namorados Via Uno. Seu namorado vai ver que acertou no presente e você vai ver que acertou no namorado".

Outro caso de adequação da publicidade - mas não de sua utilização - foi encontrado no Volume 2 de Português: Linguagens ${ }^{9}$, relativo ao anúncio do sorvete Milka, da marca Kibon, retirado da revista Atrevida, em exercício dado para o aprendizado do adjetivo. Tal anúncio apresenta a foto de um sorvete mordido e os seguintes dizeres: " $O$ sonho de toda mulher: bonito, gostoso e com recheio. Novo Milka Morango. Sorvete de baunilha mesclado com uma incrível calda de morango e cobertura crocante feita com o delicioso chocolate Milka”.

No exercício proposto, há a seguinte pergunta: "Considerando a intencionalidade do texto, isto é, a finalidade com que ele foi criado, justifique o predomínio dessa classe gramatical". Como sugestão de resposta, apresenta aos professores: "Sendo o anúncio um texto publicitário, cuja finalidade é promover um produto (no caso, um sorvete), é natural que se empreguem adjetivos capazes de ressaltar as qualidades positivas do produto". O mesmo

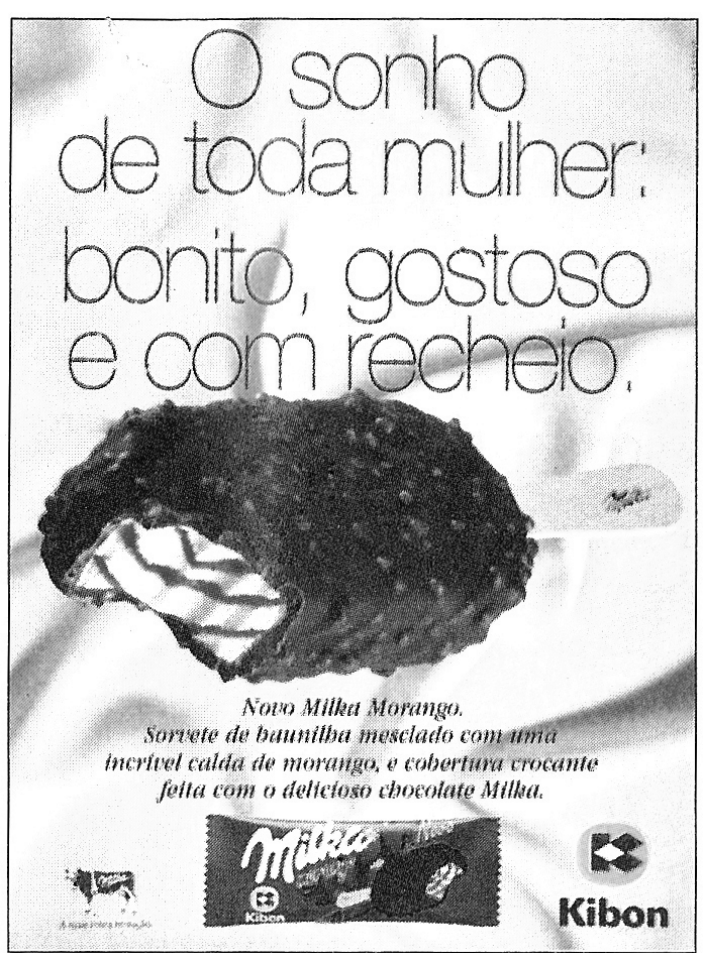

8. Ibid., p. 55 9. Ibid., v. 2, p. 59 . 
comunicação \& educação • Ano XII • Número 2 • maio/ago 2007

tipo de pergunta poderia estar relacionado a qualquer gênero de texto, já que se trata de mera assimilação do objetivo da utilização dos adjetivos, e não de uma abordagem crítica em relação à publicidade.

\section{AVALIAÇÃO DO CONTEÚDO DOS LIVROS DIDÁTICOS}

O Ministério da Educação, por intermédio da Secretaria de Educação Básica (SEB) e em parceria com o Fundo Nacional de Desenvolvimento da Educação (FNDE), implantou, em 2004, o Programa Nacional do Livro para o Ensino Médio (PNLEM), com o objetivo de avaliar os livros didáticos. O Catálogo dos Livros do Ensino Médio, enviado para as escolas públicas, contém uma síntese das obras de Língua Portuguesa e de Matemática avaliadas e aprovadas com o intuito de servir de parâmetro, auxiliando assim na escolha do material de apoio a ser usado em sala de aula pelo professor. De acordo com o gerente editorial da Atual, editora responsável pela publicação de Português: Linguagens, o maior comprador de livros didáticos no País é o governo. Ou seja, o livro aprovado na avaliação é enviado às escolas e o escolhido pelo professor será comprado pelo governo e entregue gratuitamente aos alunos ${ }^{10}$.

A presença de publicidade nos livros didáticos foi alvo de polêmica após a publicação de uma matéria no Jornal do Brasil, intitulada "Livros didáticos têm propaganda"11. A reportagem chamava a atenção para a inserção de anúncios publicitários de marcas conhecidas e suas qualidades nos livros didáticos do Ensino Médio, ressaltando que a prática constitui merchandising. Usando como parâmetro os livros Química na Abordagem do Cotidiano, volume 2, dos autores Tito \& Canto (Editora Moderna) e Língua, Literatura e Redação, volume 2, de José de Nicola (Editora Scipione), adotados pelo Colégio Mackenzie de Brasília, para o segundo ano do Ensino Médio, a matéria cita a presença de publicidades da Coca-Cola tanto no livro de Português quanto no de Química; no primeiro, para ensinar o que é um pronome indefinido e, no segundo, para exemplificar

10. Disponível em: <http://www.fnde.gov. br/home/ld_ensinomedio/portugues\%2019-042005.pdf>. Acesso em: 16 out. 2006

11. ROMERO, Cristiano. Livros didáticos têm propaganda. Jornal do Brasil, p. 10, 10 fev. 2000.

12. LEALI, Francisco. Paulo Renato condena propaganda. Jornal do Brasil p. $5 a, 11$ fev. 2000.

13. LEALI, Francisco; GIRALDI, Renata. Publicidade em livro irrita ministro. Jornal do Brasil, p. 7, 16 fev. 2000.

14. LEALI, Paulo Renato condena propaganda, cit. uma solução líquida. Outros anúncios citados foram os da marca Cisne, Café do Ponto e analgésico Bufferin.

Na época da publicação da matéria, os livros didáticos do Ensino Médio não passavam pela avaliação do Ministério da Educação, ao contrário dos destinados ao Ensino Fundamental. Diante do ocorrido, o então ministro da Educação, Paulo Renato Souza, pronunciou-se afirmando que, caso se detectasse a inserção de publicidades nos livros destinados ao Ensino Fundamental, os mesmos seriam excluídos da lista do MEC. "Livro didático não é espaço para merchandising"12, afirmou. Entretanto, o ministro declarou também que não há como coibir o procedimento, já que não é ilegal ${ }^{13}$.

Negando a existência de merchandising no livro didático de Química de sua autoria e justificando o motivo da utilização das publicidades, Eduardo Leite do Canto declarou ao jornal: "Não sou pago para citar nada. Não há merchandising no livro como há nas novelas. A idéia é usar produtos conhecidos dos alunos para contextualizar os conceitos da disciplina"14. O mesmo discurso é feito pela Editora Scipione: "A Editora Scipione, responsável pela publicação, também nega 
que receba dinheiro pela veiculação. Segundo a Editora, os anúncios fazem parte de uma filosofia recomendada pelo Ministério da Educação de aproximar o conteúdo ensinado do cotidiano do aluno"15.

Entre os anúncios publicitários encontrados pela reportagem no livro Língua, Literatura e Redação (Editora Scipione), usados para transmitir noções de gramática aos alunos, estão os das marcas Malwee e Phillips. Consultada pela reportagem, a pedagoga e ex-professora da Universidade do Estado do Rio de Janeiro, Laurinda Barbosa, diz-se contra a veiculação de merchandising e também contra a interferência do MEC em relação ao conteúdo dos livros - "Sou contra qualquer tipo de censura"16.

No decorrer da polêmica, vários educadores, consultados pela reportagem, afirmaram que condenam a inserção de anúncios publicitários nos livros didáticos, já que a consideram "prejudicial à formação das crianças"17. Entretanto, são a favor da inserção do anúncio com a ausência das marcas, que seriam cobertas por uma tarja preta, a exemplo do que é feito em outros países como Alemanha e Uruguai.

Diante da ameaça do recolhimento de alguns livros pelo MEC, a Abrelivros, entidade das editoras, se pronunciou através de carta enviada ao Ministro da Educação, na qual solicita a informação dos "procedimentos e cuidados que devem ser tomados quanto ao uso de imagem ou textos de marcas comerciais nos livros didáticos"18.

Decidido a "coibir o merchandising"19, o então Ministro da Educação Paulo Renato Souza se comprometeu a "estabelecer um critério para os livros que já estão à venda e outro para os que serão colocados no mercado" ${ }^{20}$.

Em maio de 2005, a deputada Selma Schons, do PT/PR, propôs o Projeto de Lei n. 5.136/05, que acrescenta parágrafo único ao art. 79 da Lei n. 8.069²1: "É vedada a propaganda comercial, sob qualquer forma, em livros didáticos". Vários outros projetos de lei já tentaram ora sua legalização, ora sua proibição. Contra a presença da publicidade, houve os projetos dos deputados Padre Roque (PT/PR), Schons (PT/PR, 2000), José Carlos Coutinho (PFL/RJ, 2001) e Elimar Máximo Damasceno (PRONA/SP, 2003). A favor, os projetos do deputado Henrique Eduardo Alves (PMDB/RN, 1974 e 1983).

O gerente editorial da Atual afirma que o projeto de lei é bastante restritivo em relação ao uso da publicidade e garante que não há merchandising, explicando que, em alguns casos, a própria editora precisa pagar os direitos autorais para poder publicar um anúncio publicitário no livro didático.

\section{OBSERVAÇÕES FINAIS}

$\mathrm{Na}$ tentativa de aproximar-se do cotidiano dos alunos, como verificamos, autores e editoras utilizam anúncios publicitários nos livros didáticos, assim como matérias jornalísticas, capas de revistas e livros, charges, entre outras formas de atuação da mídia.

Entendemos que esta parece ser uma tentativa de levá-los a perceber que só temos acesso à realidade contemporânea através de mediações das mais
15. Ibid

16. Ibid.

17. LIMA, Rosa. Livro estrangeiro não tem propaganda. Jornal do Brasil p. $5 a, 12$ fev. 2000 .

18. CARVALHO, Francisco. Editora se defende. Jornal do Brasil, p. 7, 16 fev. 2000.

19. GIRALDI, Renata. Livro didático não terá propaganda. Jornal do Brasil p. 5b, 3 mar. 2000 .

20. Ibid

21. Art. 79 da Lei n. 8.069, de 13 de julho de 1990 (ECA - Estatuto da Criança e do Adolescente): "As revistas e publicações destinadas ao público infanto-juvenil não poderão conter ilustrações, fotografias, legendas, crônicas ou anúncios de bebidas alcoólicas, tabaco, armas e munições, e deverão respeitar os valores éticos e sociais da pessoa e da família". 
diversas. Essas mediações têm na mídia um dos seus pilares, pois ela ajuda na construção dos significados sociais, os quais tecem a trama do existir no mundo e com o mundo, caracterizando-se como o fio mais forte no tecido que veste nossas decisões, atitudes etc., no cotidiano.

A publicidade presente nos livros didáticos de Português analisados foi usada limitadamente para algumas atividades, sobretudo para exemplificar as regras gramaticais. Passam em branco a questão da importância da mídia propriamente dita e o papel da publicidade na construção de significados.

Se isso é bom para o ensino da língua viva, é, porém, uma maneira inadequada de discussão da amplitude da mídia na sociedade contemporânea.

O diálogo aluno/professor, que tem como eixo as questões da mídia, sejam as tradicionais, sejam as novas ou novíssimas, é urgente, necessário e indispensável à formação da consciência do aluno, das mediações existentes entre ele e a realidade, e que são construídas sobretudo pela mídia. Este é um dos caminhos para que nossos jovens alcancem a recepção crítica.

O livro didático, ao reproduzir um anúncio publicitário, deveria se empenhar também na construção do cidadão crítico. Citando como exemplo o anúncio publicitário do Microondas Electrolux, mostrado pelo livro didático Português (Maia), o enunciado faz o seguinte questionamento: "De que recurso se valeu o anunciante para disfarçar os juros extorsivos cobrados no financiamento do produto?". A resposta, como é sugerida pelo livro, diz respeito às palavras encargo mensal, que corresponderiam aos juros cobrados, mas sem necessariamente utilizar a palavra juros, que carrega uma carga semântica negativa. A discussão, porém, pára por aí. Não seria uma boa chance de debater sobre as palavras ocultando realidades, velando o exercício das reivindicações?

Assim se pode colaborar para a formação do cidadão crítico.

Resumo: Inserindo-se no campo comunicação/educação, esta crítica procura verificar como a publicidade se apresenta nos livros didáticos destinados a jovens do Ensino Médio. Para tanto, tomamos os anúncios publicitários inseridos nos livros mais usados: um volume único e um seriado, totalizando, portanto, quatro livros. Através de uma análise primeiramente quantitativa, e, depois, qualitativa, verificamos os modos mais recorrentes das sugestões de exploração dos anúncios publicitários em sala de aula. O resultado nos revelou que as atividades propostas, ainda que interessantes para os estudos de língua, não contemplam, em nenhum momento, a discussão da publicidade na construção de significados e da mídia no tecido da cultura, temas prioritários na contemporaneidade.

Palavras-chave: crítica, educação, publicidade, livro didático, recepção.
Abstract: Inserted in the field of communication and education, this criticism verifies how advertisement is presented in textbooks for youngsters of high school. For that, we took advertisements inserted in the most used textbooks - one of them in an only volume and the other one, a textbook series -, therefore a total of four books. Through an analysis that was primarily quantitative and, later, qualitative, we verified the most repeated advertisements sorts of exploration in classroom. The result showed us that the proposed activities, although interesting for language studies, do not cover, in any moment, the discussion of advertisement in the building of meaning and media in the cultural texture, a prior subject of discussion in contemporaneity.

Keywords: criticism, education, advertisement, textbook, reception. 